\title{
Quality of standing balance in community-dwelling elderly: Age-related differences in single and dual task conditions
}

\author{
Tiago Coelho ${ }^{\mathrm{a}}$, Ângela Fernandes ${ }^{\mathrm{a}, \mathrm{b}}$, Rubim Santos ${ }^{\mathrm{a}, \mathrm{b}}$, Constança Paúl ${ }^{\mathrm{c}, \mathrm{d}}$, Lia Fernandes ${ }^{\mathrm{d}, \mathrm{e}}$
}

\author{
a School of Allied Health Technologies, Polytechnic Institute of Porto, Portugal \\ ${ }^{\mathrm{b}}$ Activity and Human Movement Study Center, School of Allied Health Technologies, Polytechnic Institute of Porto, Portugal \\ ${ }^{c}$ Institute of Biomedical Sciences Abel Salazar, University of Porto, Portugal \\ d Center for Health Technology and Services Research, Faculty of Medicine, University of Porto, Portugal \\ ${ }^{\mathrm{e}}$ Faculty of Medicine, University of Porto, Portugal
}

\begin{abstract}
A B S T R A C T
Aim: To examine the relationship between age and quality of standing balance in single and dual task conditions.

Methods: A cross-sectional study was conducted using a sample of 243 community-dwellers aged $\geq 65$ years. Quality of standing balance was assessed by measuring the center of pressure (COP) sway with a pressure platform. Measurements were performed under single task (orthostatic position) and dual task (orthostatic position while performing a verbal fluency task) conditions.

Results: The mean age of the participants was $79.1( \pm 7.3)$ years and $76.1 \%$ were women. Older age was associated with an increased COP sway, mainly in the medial/lateral (ML) direction. Most COP sway parameters were higher under dual task conditions than under single task. After controlling for the effect of the number of words enunciated in dual task conditions, only the differences in COP sway parameters in the ML direction remained significant. There was no significant interaction between age group (65-79; $\geq 80$ years) and condition, which indicates that differences in COP sway caused by performing a secondary task were similar for younger and for older participants.

Conclusion: Age did not seem to influence significantly the decline in the quality of standing balance triggered by performing a concurrent cognitive task. However, older age was consistently associated with poorer standing balance, both in single and in dual task conditions. Therefore, performing a secondary task may lead older individuals to reach their postural stability limits and, consequently, to fall.
\end{abstract}

Keywords: Elderly Dual task Standing balance

\section{Introduction}

The ability to maintain standing balance influences the risk of falling while performing everyday activities (Piirtola \& Era, 2006; Zijlstra, Ufkes, Skelton, Lundin-Olsson, \& Zijlstra, 2008). Particularly in the elderly population, falls are a major health problem (Gelbard et al., 2014; Takeshima et al., 2014). Indeed, mainly due to the high prevalence of comorbidity and frailty, the clinical outcomes of falling are worse for older adults than for younger individuals (Gelbard et al., 2014). These adverse consequences include fractures, prolonged hospitalization, disability, institutionalization and death (Ayoung-Chee et al., 2014; Gelbard et al., 2014; Rubenstein, 2006).
As age increases, neuromusculoskeletal and sensorial changes may lead to an impaired postural control and difficulties in maintaining balance (Hiyamizu, Morioka, Shomoto, \& Shimada, 2012; Takeshima et al., 2014; Winter, 1995). The loss of muscle fibers and the decline in the amount of force that each fiber can produce are examples of age-related modifications in muscle properties that have an impact on postural stability (Bello-Haas, 2009). Concomitantly, the function of the visual, vestibular and proprioceptive systems, which provide crucial information for an effective postural control, also suffers a deterioration with aging, thus influencing balance (Bello-Haas, 2009).

However, it is similarly important to consider that preserving balance in daily activities also depends on cognition, particularly attentional resources (Doumas \& Krampe, 2016; Swanenburg, de Bruin, Uebelhart, \& Mulder, 2009; Zijlstra et al., 2008). Usually, a 
single task such as postural control may be performed requiring minimal attention, but when a person is presented with a secondary task (e.g. having to answer a question), task-related cognitive demands increase, and attentional resources have to be divided between both tasks (Doumas \& Krampe, 2016; Kang \& Lipsitz, 2010; Woollacott \& Shumway-Cook, 2002). Performance in simultaneous tasks is thus influenced by the ability to effectively focus attention in concurrent stimuli. This flexible control of attention, a cognitive function associated with the frontal lobes of the brain and with executive functioning, seems to be impaired in older adults (Glisky, 2007; Sheridan, Solomont, Kowall, \& Hausdorff, 2003; Yogev, Hausdorff, \& Giladi, 2008). Therefore, elderly individuals may have an increased difficulty to maintain balance while performing activities that require multitasking (Doumas \& Krampe, 2016; Hiyamizu et al., 2012; Piirtola \& Era, 2006). Nonetheless, there is conflicting evidence regarding how secondary tasks influence postural stability in older adults (Bergamin et al., 2014; Boisgontier et al., 2013; Swanenburg et al., 2009).

Maintaining standing balance relies upon the ability to keep the body's center of mass inside the base of support while in an upright position (Pasma et al., 2014). The corrective forces that control the center of mass can be measured by assessing center of pressure (COP) sway, which represents the vertical ground reaction forces (Moghadam et al., 2011; Pasma et al., 2014). This assessment allows for the detection of subtle changes in postural stability and, consequently, COP sway can be considered as an indicator of quality of balance (Moghadam et al., 2011; Pasma et al., 2014; Takeshima et al., 2014).

A better understanding of how age influences standing balance under single and dual task conditions, as well as an increased insight regarding the impact of specific secondary tasks on postural stability, would allow for an enhanced comprehension of the risk of falling of older adults. Therefore, the aim of the present study was to examine the relationship between age and quality of standing balance (assessed by measuring COP sway parameters) in single and dual task conditions, in a sample of community-dwelling elderly. Particularly, this study intended to test the following hypotheses: (1) if older age is associated with a higher COP sway; (2) if performing a secondary task is associated with an increased COP sway; (3) if the effect of performing a secondary task on COP sway is greater for older individuals.

\section{Methods}

\subsection{Study design and participants}

A cross-sectional study was conducted using a non-probabilistic sample of 243 community-dwelling elderly ( $\geq 65$ years) individuals from Porto, Portugal. After information about the study was disclosed in local institutions, 257 elderly volunteered to participate. Exclusion criteria consisted of severe physical, sensorial or cognitive impairments, as well as inability to speak Portuguese. Two individuals were excluded as result of being unable to stand, two were excluded due to recent history of stroke, one was excluded for having a fractured foot, one was excluded for reporting major feet sensory loss and five were excluded due to severe cognitive deficits (i.e., scored $<10$ in Mini Mental State Examination (Folstein, Folstein, \& McHugh, 1975; Guerreiro, Botelho, Leitão, Castro-Caldas, \& Garcia, 1994), according to guidelines of the National Institute for Health and Care Excellence (NICE, 2011)). Three participants were not included in the study after refusing to complete the assessment.

Data collection was carried out by trained researchers, using structured assessment protocols. The study was approved by institutional review boards and by the ethics committee of the Ph.
D.in Gerontology and Geriatrics (Institute of Biomedical Sciences Abel Salazar-University of Porto). All participants gave their written informed consent.

\subsection{Measurements}

A questionnaire was used to assess the sociodemographic characteristics of the participants. Cognitive deficit and depression were screened using the Mini Mental State Examination (MMSE) (Folstein et al., 1975; Guerreiro et al., 1994) and the 15-item version of the Geriatric Depression Scale (GDS-15) (Sheikh \& Yesavage, 1986; Simões, Prieto, Pinho, Sobral, \& Firmino, 2015), respectively. Height and weight were also measured in order to calculate the participants' Body Mass Index (BMI).

Quality of standing balance was assessed by measuring COP sway parameters (total path length, average velocity, maximum velocity, and maximum range) both in medial/lateral (ML) and anterior/posterior (AP) directions. These measurements were performed using a pressure platform (Emed-AT25 D, Novel Inc., Munich, Germany), which contained 4000 capacitive sensors within a sensing area of $380 \times 240 \mathrm{~mm}^{2}$ (sensor resolution of two sensors $/ \mathrm{cm}^{2}$ ), and had a $25 \mathrm{~Hz}$ recording frequency.

Balance in single task was examined by requiring the participants to stand on the platform and to maintain an orthostatic position for $60 \mathrm{~s}$. To assess balance under dual task conditions, participants were asked to maintain an orthostatic position for the same period of time while performing an additional verbal fluency task. This latter measurement was performed twice, with different tasks (Fernandes et al., 2015): a semantic fluency task (subjects had to enunciate as many species of animals as possible during $60 \mathrm{~s}$ ) and phonemic fluency task (individuals had to enunciate as many words as possible beginning with the letter $\mathrm{R}$ within the same period). In the present study, the mean number of enunciated words and the mean COP sway parameters were calculated (from both measurements in dual task) in order to produce a single score for dual task performance.

All subjects were asked to perform the balance tasks while barefooted and looking directly at a target placed two meters away at the height of the participants' eyes. The order of each condition was randomized to avoid possible fatigue and learning effect. Only the most stable 30 s period of each measurement was considered.

\subsection{Statistical analysis}

The characteristics of the participants are reported using proportions and measures of central tendency and dispersion. Hierarchical regression analyses were conducted to examine if age allows for the prediction of each COP sway parameter, both in single and in dual task conditions, after adjusting for the effect of the following covariates: sex, education, BMI, cognitive deficit and depression. Mixed ANOVA analyses of variance were conducted to ascertain if any change in COP sway between conditions (single $x$ dual) is different across age groups (65-79 years $\times \geq 80$ years), i.e. if there is an interaction effect. Differences in COP parameters between conditions (within-subjects) and between age groups (between-subjects) are also presented separately. Results of the mixed ANOVA analyses are reported with adjustment to sex, education, BMI, cognitive deficit and depression. Secondarily, the mixed ANOVA analyses were repeated adjusting for the effects of an additional variable: the number of words enunciated in dual task.

Two-tailed tests were used throughout all analyses and a $p$ value $<0.05$ was considered statistically significant. All statistical analyses were performed with IBM SPSS Statistics 22.0 (SPSS, Inc., Chicago, IL, USA). 


\section{Results}

This study comprises a sample of 243 elderly individuals, of which $51.4 \%$ were aged $\geq 80$ years and $76.1 \%$ were women. The mean BMI of the participants was $28.6( \pm 5.4)$. The mean MMSE and GDS score were $23.7( \pm 4.9)$ and $5.4( \pm 3.9)$, respectively. The proportion of individuals with cognitive deficit was $51.9 \%$, while $43.6 \%$ of the participants showed depression. See Table 1 for further details about the characteristics of the participants, including COP sway parameters.

The results of the hierarchical regression analyses (Table 2) indicated that age significantly predicted most of the COP sway parameters, both in single and in dual task conditions. In general, increasing age was associated with higher COP sway values.

Differences between younger and older individuals regarding COP sway were further highlighted through mixed ANOVA analyses (Table 3). Indeed, with the exception of the COP maximum range in the AP direction, there were significant differences between participants aged 65-79 years and individuals with $\geq 80$ years in every COP sway parameter, independently of the effect of the covariates.

There were also significant differences between conditions (single $\times$ dual task) in every COP sway parameter, with the exception of maximum range in the AP direction, after adjusting for sex, education, BMI, cognitive deficit and depression. However, after controlling for the effect of the number of words enunciated in the dual task conditions, differences in total path length in the

Table 1

Characteristics of the participants $(n=243)$.

\begin{tabular}{|c|c|}
\hline Characteristics & $\mathrm{n}(\%)$ \\
\hline \multicolumn{2}{|l|}{ Sociodemographic characteristics } \\
\hline Age (years), mean $\pm S D$ & $79.1 \pm 7.3$ \\
\hline $65-79$ & $118(48.6)$ \\
\hline$\geq 80$ & $125(51.4)$ \\
\hline$\overline{\text { Sex }}$ (women) & $185(76.1)$ \\
\hline Education (years), mean $\pm S D$ & $4.4 \pm 3.6$ \\
\hline \multicolumn{2}{|l|}{ Anthropometry } \\
\hline Height (meters), mean \pm SD & $1.55 \pm 0.1$ \\
\hline Weight $(\mathrm{kg})$, mean $\pm \mathrm{SD}$ & $68.8 \pm 13.8$ \\
\hline BMI $\left(\mathrm{kg} / \mathrm{m}^{2}\right)$, mean $\pm \mathrm{SD}$ & $28.6 \pm 5.4$ \\
\hline \multicolumn{2}{|l|}{ Psychological characteristics } \\
\hline MMSE $(0-30)$, mean \pm SD & $23.7 \pm 4.9$ \\
\hline Cognitive deficit $^{\mathrm{a}}$ & $126(51.9)$ \\
\hline GDS (0-15), mean $\pm S D$ & $5.4 \pm 3.9$ \\
\hline Depression $^{\mathrm{b}}$ & $106(43.6)$ \\
\hline \multicolumn{2}{|l|}{ COP sway parameters } \\
\hline \multicolumn{2}{|l|}{ Single task-ML direction } \\
\hline Total path length $(\mathrm{cm})$, mean $\pm S D$ & $16.0 \pm 7.7$ \\
\hline Average velocity $(\mathrm{cm} / \mathrm{s})$, mean $\pm S D$ & $0.5 \pm 0.3$ \\
\hline Maximum velocity $(\mathrm{cm} / \mathrm{s})$, mean $\pm S D$ & $2.4 \pm 1.3$ \\
\hline Maximum range $(\mathrm{cm})$, mean $\pm S D$ & $1.7 \pm 0.9$ \\
\hline \multicolumn{2}{|l|}{ Single task-AP direction } \\
\hline Total path length $(\mathrm{cm})$, mean $\pm S D$ & $20.3 \pm 8.4$ \\
\hline Average velocity $(\mathrm{cm} / \mathrm{s})$, mean $\pm S D$ & $0.7 \pm 0.3$ \\
\hline Maximum velocity $(\mathrm{cm} / \mathrm{s})$, mean $\pm S D$ & $2.9 \pm 1.3$ \\
\hline Maximum range $(\mathrm{cm})$, mean $\pm S D$ & $1.9 \pm 0.7$ \\
\hline \multicolumn{2}{|l|}{ Dual task-ML direction } \\
\hline Total path length $(\mathrm{cm})$, mean $\pm \mathrm{SD}$ & $19.2 \pm 8.9$ \\
\hline Average velocity $(\mathrm{cm} / \mathrm{s})$, mean $\pm S D$ & $0.6 \pm 0.3$ \\
\hline Maximum velocity $(\mathrm{cm} / \mathrm{s})$, mean $\pm S D$ & $3.0 \pm 1.7$ \\
\hline Maximum range $(\mathrm{cm})$, mean $\pm S D$ & $2.1 \pm 1.0$ \\
\hline \multicolumn{2}{|l|}{ Dual task-AP direction } \\
\hline Total path length $(\mathrm{cm})$, mean $\pm S D$ & $23.7 \pm 9.2$ \\
\hline Average velocity $(\mathrm{cm} / \mathrm{s})$, mean $\pm S D$ & $0.8 \pm 0.3$ \\
\hline Maximum velocity $(\mathrm{cm} / \mathrm{s})$, mean $\pm S D$ & $3.6 \pm 1.6$ \\
\hline Maximum range $(\mathrm{cm})$, mean $\pm S D$ & $2.2 \pm 0.7$ \\
\hline \multicolumn{2}{|l|}{ Verbal fluency task } \\
\hline Number of words enunciated, mean $\pm S D$ & $7.3 \pm 3.4$ \\
\hline
\end{tabular}

a Cognitive deficit: MMSE score $\leq 22$ for $0-2$ years of education; $\leq 24$ for $3-6$ years; and $\leq 27$ for $\geq 7$ years.

b Depression: GDS-15 score $\geq 5$.
Table 2

Prediction of COP sway parameters under single and dual task conditions with age.

\begin{tabular}{|c|c|c|c|c|}
\hline \multirow[t]{2}{*}{ COP sway parameters } & \multicolumn{2}{|c|}{ Single task } & \multicolumn{2}{|c|}{ Dual task } \\
\hline & $\beta$ & p-value & $\beta$ & p-value \\
\hline \multicolumn{5}{|l|}{ ML direction } \\
\hline Total path length & 0.22 & $<0.01$ & 0.21 & $<0.01$ \\
\hline Average velocity & 0.22 & $<0.01$ & 0.21 & $<0.01$ \\
\hline Maximum velocity & 0.23 & $<0.01$ & 0.15 & $<0.05$ \\
\hline Maximum range & 0.14 & 0.06 & 0.17 & $<0.05$ \\
\hline \multicolumn{5}{|l|}{ AP direction } \\
\hline Total path length & 0.23 & $<0.01$ & 0.18 & $<0.05$ \\
\hline Average velocity & 0.23 & $<0.01$ & 0.18 & $<0.05$ \\
\hline Maximum velocity & 0.21 & $<0.01$ & 0.11 & 0.12 \\
\hline Maximum range & 0.10 & 0.19 & -0.04 & 0.62 \\
\hline
\end{tabular}

Standardized regression coefficient is presented $(\beta)$. Independent variable was age. Prediction of single task COP parameters adjusted for sex, education, BMI, cognitive deficit and depression.

Table 3

Effects of dual task and age group (65-79; $\geq 80$ years) on COP sway parameters.

\begin{tabular}{|c|c|c|c|}
\hline & \multirow[b]{2}{*}{ Effect } & \multicolumn{2}{|l|}{ p-value } \\
\hline & & Adjustment $^{\mathrm{a}}$ & Adjustment $^{\mathrm{b}}$ \\
\hline \multicolumn{4}{|l|}{ ML direction } \\
\hline \multirow[t]{3}{*}{ Total path length } & Condition (within-subjects) & $<0.01$ & $<0.05$ \\
\hline & $\begin{array}{l}\text { Age group (between- } \\
\text { subjects) }\end{array}$ & $<0.001$ & $<0.001$ \\
\hline & Interaction & 0.46 & 0.42 \\
\hline \multirow[t]{3}{*}{ Average velocity } & Condition (within-subjects) & $<0.001$ & $<0.05$ \\
\hline & $\begin{array}{l}\text { Age group (between- } \\
\text { subjects) }\end{array}$ & $<0.001$ & $<0.001$ \\
\hline & Interaction & 0.55 & 0.51 \\
\hline \multirow{3}{*}{$\begin{array}{l}\text { Maximum } \\
\text { velocity }\end{array}$} & Condition (within-subjects) & $<0.01$ & 0.09 \\
\hline & $\begin{array}{l}\text { Age group (between- } \\
\text { subjects) }\end{array}$ & $<0.001$ & $<0.001$ \\
\hline & Interaction & 0.72 & 0.68 \\
\hline \multirow[t]{3}{*}{ Maximum range } & Condition (within-subjects) & $<0.001$ & $<0.01$ \\
\hline & $\begin{array}{l}\text { Age group (between- } \\
\text { subjects) }\end{array}$ & $<0.01$ & $<0.01$ \\
\hline & Interaction & 0.36 & 0.36 \\
\hline \multicolumn{4}{|l|}{ AP direction } \\
\hline \multirow{3}{*}{ Total path length } & Condition (within-subjects) & $<0.01$ & 0.07 \\
\hline & $\begin{array}{l}\text { Age group (between- } \\
\text { subjects) }\end{array}$ & $<0.01$ & $<0.01$ \\
\hline & Interaction & 0.90 & 0.94 \\
\hline \multirow[t]{3}{*}{ Average velocity } & Condition (within-subjects) & $<0.01$ & 0.05 \\
\hline & $\begin{array}{l}\text { Age group (between- } \\
\text { subjects) }\end{array}$ & $<0.01$ & $<0.01$ \\
\hline & Interaction & 0.96 & 0.93 \\
\hline \multirow{3}{*}{$\begin{array}{l}\text { Maximum } \\
\text { velocity }\end{array}$} & Condition (within-subjects) & $<0.05$ & 0.18 \\
\hline & $\begin{array}{l}\text { Age group (between- } \\
\text { subjects) }\end{array}$ & $<0.05$ & $<0.05$ \\
\hline & Interaction & 0.59 & 0.62 \\
\hline \multirow[t]{3}{*}{ Maximum range } & Condition (within-subjects) & 0.93 & 0.23 \\
\hline & $\begin{array}{l}\text { Age group (between- } \\
\text { subjects) }\end{array}$ & 0.87 & 0.86 \\
\hline & Interaction & 0.42 & 0.43 \\
\hline
\end{tabular}

a Adjustment to sex, education, BMI, cognitive deficit and depression.

b Adjustment to sex, education, BMI, cognitive deficit, depression and number of words enunciated in dual task.

AP direction, average velocity in the AP direction and maximum velocity in the ML and AP directions were no longer significant.

Finally, there was no significant interaction between age group and condition, after adjusting for covariates. This indicates that the differences between single and dual task in COP sway parameters presented by individuals aged 65-79 years were not statistically different from those presented by individuals with $\geq 80$ years. Indeed, an examination of Fig. 1 also suggests that changes in COP sway between single and dual task are very similar for younger and older subjects. 


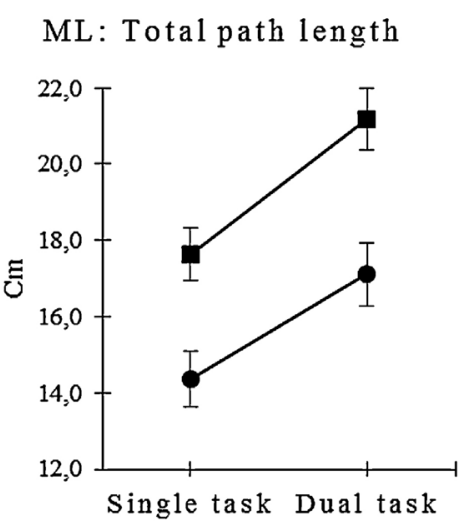

ML: Average velocity

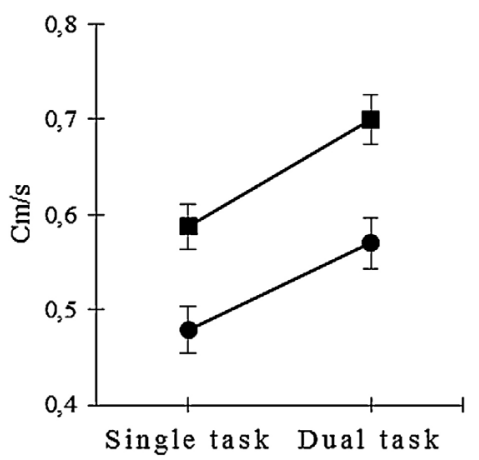

ML: Maximum velocity

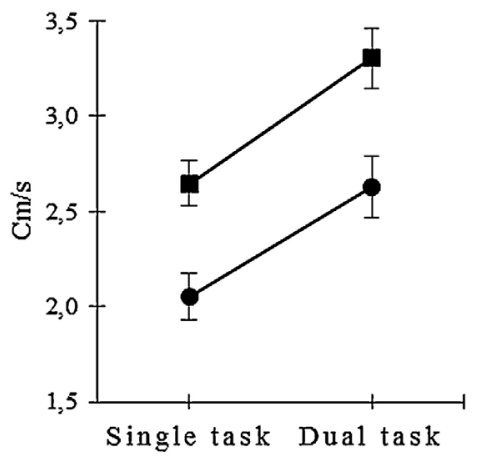

ML: Maximum range

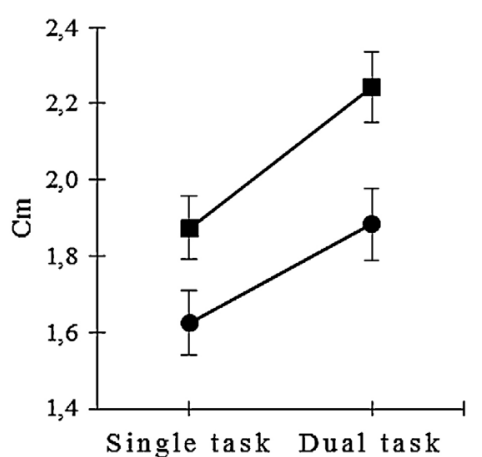

AP: Total path length

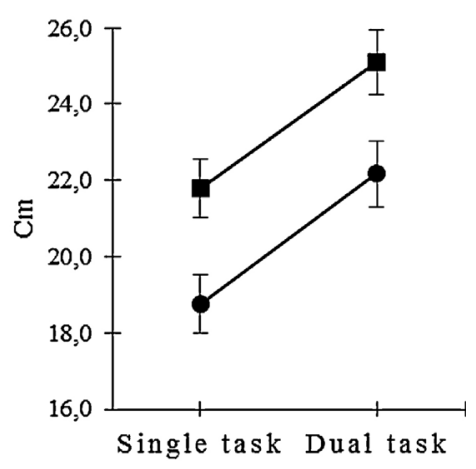

AP: Average velocity

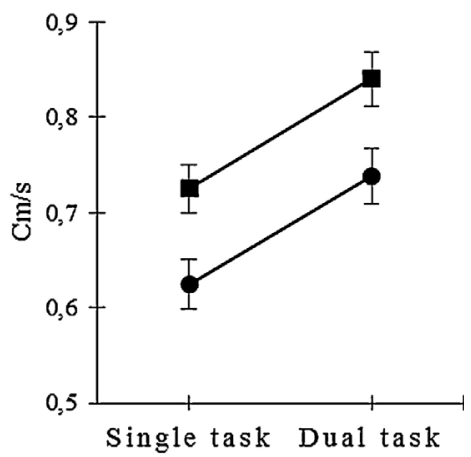

AP: Maximum velocity

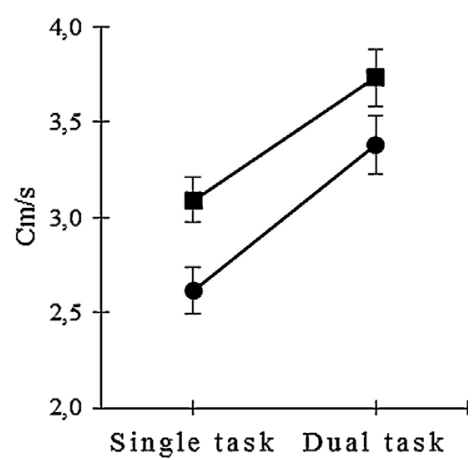

AP: Maximum range *

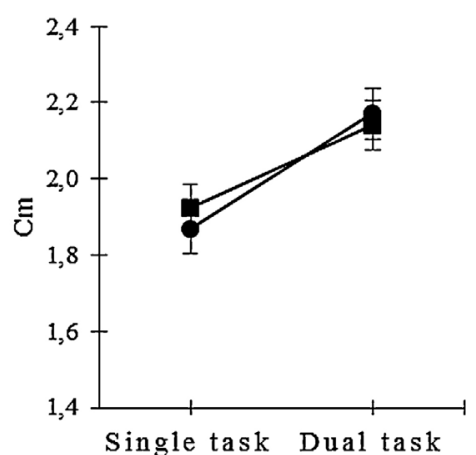

Fig. 1. Comparison of COP sway parameters in single and dual task conditions by age groups (65-79 years; $\geq 80$ years) Estimated marginal means and standard errors (adjusted for sex, education, BMI, cognitive deficit and depression) for each COP sway parameter (in ML and AP directions) are presented by age groups (65-79 years; $\geq 80$ years) $\times$ Differences between age group and between conditions were non-significant. 


\section{Discussion}

In the present study, the quality of standing balance (examined by measuring COP sway parameters) of community-dwelling elderly was significantly associated with age, both in single and in dual task conditions. In general, older individuals had worse standing balance than younger ones. Concomitantly, it was found that the effect of performing a secondary task on standing balance was significant, considering the variance of most of the selected COP sway parameters. However, after controlling for the effect of the number of words enunciated under dual task conditions, the differences in balance between single and dual task performance were less evident. On the other hand, performing a secondary task had a similar effect in the standing balance of younger (65-79 years) and older individuals ( $\geq 80$ years).

As expected due to the physical impact of aging (Bello-Haas, 2009), older subjects presented a higher COP sway while standing, which indicates a poorer ability to maintain postural control and balance. Age was associated with COP sway in both directions, but with more parameters in the ML direction than in the AP direction. Several studies have found that COP sway data are reliable measurements to detect age-related differences in quality of standing balance (Bergamin et al., 2014; Moghadam et al., 2011; Pasma et al., 2014). Evidence shows that older age seems to be associated with an increased COP sway particularly in the ML direction, which in turn is thought to be a more important predictor of falls than sway in the AP direction (Kang \& Lipsitz, 2010; Pasma et al., 2014; Piirtola \& Era, 2006). This may explain, in part, the high prevalence of falls in elderly populations.

In the present study, the overall quality of standing balance decreased while performing a secondary verbal fluency task. Considering that COP sway measurements detect subtle changes in postural stability, these results could be explained by the increased respiratory muscle activity in relation to vocalization (Bergamin et al., 2014; Swanenburg et al., 2009). However, previous research has found that the disturbing effect on balance caused simply by the motor aspect of articulation was significantly lower than the effect produced by a verbal attention-demanding task (Swanenburg et al., 2009). It is important to consider that the level of cognitive demand of the secondary task is critical to determine the amount of attentional resources allocated to it, in detriment of the resources allocated to postural control (Boisgontier et al., 2013; Gelbard et al., 2014; Kang \& Lipsitz, 2010). Taking this into account, the differences in standing balance between single and dual task conditions were also analyzed after controlling for the effect of the amount of words enunciated. It was possible to observe that independently of the vocalization, there were still differences between conditions, particularly regarding COP total path length, average velocity and maximum range in the ML direction. These results support the hypothesis that the complexity of the verbal fluency tasks was enough to significantly stress the available cognitive resources and, consequently, to negatively affect postural stability. Particularly in younger adults, there is evidence of low-demanding secondary cognitive tasks contributing to balance improvement as a result of slightly shifting the focus away from postural control, increasing the automatic processing of posture (Bergamin et al., 2014; Lacour, Bernard-Demanze, \& Dumitrescu, 2008). Nonetheless, in older adults, there is a general agreement that when a secondary cognitive task is complex enough to reach/exceed cognitive resource limits, the ability to maintain balance is impaired (Lacour et al., 2008; Woollacott \& Shumway-Cook, 2002). This results from an agerelated increase in the minimum required level of controlled posture processing (i.e. increase of the cognitive demand of postural control) and, consequently, from a higher susceptibility to interference in terms of shared recruitment of neural structures (Boisgontier et al., 2013; Lacour et al., 2008; Swanenburg et al., 2009).
However, in this study, older participants were able to manage a secondary task apparently as well as younger subjects. This finding, which is in accordance with current evidence regarding the preservation of standing balance in stable conditions (Boisgontier et al., 2013), could be explained by a similar ability of the youngest old and of the oldest old to divide attention between quiet standing and additional cognitive tasks. On the other hand, as older adults consistently exhibited a worse balance across conditions than younger individuals, they could have allocated fewer attentional resources to the cognitive task than their younger counterparts, in order to focus mainly on the postural task and to prevent excessive instability and falling. Older adults with $\geq 80$ years tend to be particularly frail and to present high levels of comorbidity. Therefore, as avoiding falls might be of critical-survival value for these individuals, the prioritization of postural control at the expense of cognitive task performance seems to be a reasonable defensive mechanism (Doumas \& Krampe, 2016; Lacour et al., 2008). Research has shown that a "posture first" behaviour is a commonly employed strategy to successfully cope with agerelated deterioration (Doumas \& Krampe, 2016; Lacour et al., 2008).

It is important to consider that the findings of the present study report only to the preservation of standing balance in stable conditions. There is evidence of clear age-related differences in the effect of multitasking in more complex and dynamic postural tasks (Boisgontier et al., 2013). As more postural adjustments are required to maintain balance under unstable conditions, additional neural resources need to be recruited for postural control (Boisgontier et al., 2013). Considering that older adults need more attentional resources than younger individuals to maintain postural stability, the performance of a complex postural task is more likely affected by concurrent stimuli in older ages (Boisgontier et al., 2013).

Recommendations for studies regarding the effect of performing under dual task conditions state that the influence of practice should be controlled and that the concurrent task should be difficult enough to reach/exceed the neural resource limits (Boisgontier et al., 2013). In the present study, the balance measurement protocol ensured that order of performing under each condition was random to avoid possible fatigue and learning effect. Furthermore, the selected verbal fluency tasks were complex enough to produce differences in balance between conditions.

The statistical analyses performed in this study involved controlling for the effect of a group of variables that could have influenced balance and/or performance in the secondary cognitive task (Hardy et al., 2013; Kim et al., 2010; Nebes et al., 2001), specifically sex, BMI, education, cognitive impairment and depression. However, the fact that no adjustment or exclusion was performed considering the presence of specific diseases or the use of particular medication which could have influenced the performance in the tests, can be considered as a major limitation of this study. Nonetheless, participants with severe physical, sensorial or cognitive impairments were excluded, in order to minimize the effect of comorbidity. The lack of a detailed assessment of the participants' physical activity and inclusion in exercise protocols can also be considered as a limitation of the present study, as this information could be critical to understand the participants' performance. Finally, it is also important to refer that the small sample size and the sampling method could have limited the generalization of the results.

In conclusion, it was possible to ascertain that older age was associated with a decrease in quality of standing balance, in a sample of community-dwelling individuals with $\geq 65$ years. The quality of balance significantly declined under dual task conditions, and that this variation was similar for younger and older 
participants. However, it is important to consider that the consequences of an analogous decline in postural stability caused by performing a secondary task may be different for distinct age groups. Taking into account that older subjects consistently presented a worse balance across conditions than their younger counterparts, the effect of performing a secondary task may lead older individuals to reach their postural stability limits and to fall. In contrast, the same degree of decline in quality of balance may not be sufficient for younger individuals to reach their stability limits. This fact, combined with the evidence that falls have worse clinical outcomes for older persons, highlights the need for interventions that reduce fall risk in the elderly population. Consequently, future research should mainly focus on determining which interventions improve the ability to multitask while maintaining balance in different conditions, particularly in older individuals. Considering that most everyday activities include simultaneous postural and cognitive tasks, research in this area is of the utmost importance. Current evidence regarding the effects of tailored interventions on balance and dual task performance is promising but inconclusive, mainly due to the lack of a standardized outcome measurement (Agmon, Belza, Nguyen, Logsdon, \& Kelly, 2014; Gobbo, Bergamin, Sieverdes, Ermolao, \& Zaccaria, 2014; Zanotto et al., 2014). However, it seems that dual task training yields better results than single task training regarding the improvement of postural control in dual task conditions (Agmon et al., 2014). Nonetheless, it is still not clear if these improvements have a significant impact on function in daily life (Agmon et al., 2014). Therefore, outcome measures in future studies should include the objective assessment of the performance of everyday activities that require multitasking, preferably in the usual setting in which the elderly perform the selected activities.

\section{Conflict of interest}

The authors declare no conflict of interest.

\section{Acknowledgments}

The authors thank all the elderly participants and professionals who assisted and made the data collection possible. They particularly thank occupational therapy students (Alice Rocha, Joana Oliveira, Libânia Silva, Nicole Câmara, Rute Ferreira, Sara Santos, Stefanie Morais and Sylvie Abreu) for collecting part of the data.

\section{References}

Agmon, M., Belza, B., Nguyen, H. Q., Logsdon, R. G., \& Kelly, V. E. (2014). A systematic review of interventions conducted in clinical or community settings to improve dual-task postural control in older adults. Clinical Interventions in Aging, 9, 477492.

Ayoung-Chee, P., McIntyre, L., Ebel, B. E., Mack, C. D., McCormick, W., \& Maier, R. V. (2014). Long-term outcomes of ground-level falls in the elderly. The Journal of Trauma and Acute Care Surgery, 76(2), 498-503 [discussion].

Bello-Haas, V. D. (2009). Neuromusculoskeletal and movement function, In B. R. Bonder, \& V. D. Bello-Haas (Eds.), Functional performance in older adults (pp. 130 176).3rd ed. Philadelphia: F. A. Davis Company.

Bergamin, M., Gobbo, S., Zanotto, T., Sieverdes, J. C., Alberton, C. L., Zaccaria, M., et al (2014). Influence of age on postural sway during different dual-task conditions. Frontiers in Aging Neuroscience, 6, 271.

Boisgontier, M. P., Beets, I. A. M., Duysens, J., Nieuwboer, A., Krampe, R. T., \& Swinnen, S. P. (2013). Age-related differences in attentional cost associated with postura dual tasks: increased recruitment of generic cognitive resources in older adults. Neuroscience E Biobehavioral Reviews, 37(8), 1824-1837.

Doumas, M., \& Krampe, R. T. (2016). Ecological relevance determines task priority in older adults' multitasking. The Journals of Gerontology Series B: Psychological Sciences and Social Sciences2013.
Fernandes, Coelho, T., Vitória, A., Ferreira, A., Santos, R., Rocha, N., et al. (2015). Standing balance in individuals with Parkinson's disease during single and dualtask conditions. Gait E' Posture, 42(3), 323-328.

Folstein, M. F., Folstein, S. E., \& McHugh, P. R. (1975). Mini-mental state: a practical method for grading the cognitive state of patients for the clinician. Journal of Psychiatric Research, 12(3), 189-198.

Gelbard, R., Inaba, K., Okoye, O. T., Morrell, M., Saadi, Z., Lam, L., et al. (2014). Falls in the elderly: a modern look at an old problem. American Journal of Surgery, 208 (2), 249-253.

Glisky, E. (2007). Changes in cognitive function in human aging. In D. R. Riddle (Ed.), Brain aging: models, methods, and mechanismsBoca Raton (FL): CRC Press.

Gobbo, S., Bergamin, M., Sieverdes, J. C., Ermolao, A., \& Zaccaria, M. (2014). Effects of exercise on dual-task ability and balance in older adults: a systematic review. Archives of Gerontology and Geriatrics, 58(2), 177-187.

Guerreiro, M. P. S. A., Botelho, M., Leitão, O., Castro-Caldas, A., \& Garcia, C. (1994). Adaptação à população portuguesa do mini mental state examination (MMSE) [Adaptation of the mini mental state examination's translation to the portuguese population]. Revista Portuguesa De Neurologia, 1(9), s1.

Hardy, R., Cooper, R., Aihie Sayer, A., Ben-Shlomo, Y., Cooper, C., Deary, I. J., et al. (2013). Body mass index, muscle strength and physical performance in older adults from eight cohort studies: the HALCyon programme. PLoS One, 8(2), e56483.

Hiyamizu, M., Morioka, S., Shomoto, K., \& Shimada, T. (2012). Effects of dual task balance training on dual task performance in elderly people: a randomized controlled trial. Clinical Rehabilitation, 26(1), 58-67.

Kang, H. G., \& Lipsitz, L. A. (2010). Stiffness control of balance during quiet standing and dual task in older adults: the MOBILIZE Boston Study. Journal of Neurophysiology, 104(6), 3510-3517.

Kim, J. W., Eom, G. M., Kim, C. S., Kim, D. H., Lee, J. H., Park, B. K., et al. (2010). Sex differences in the postural sway characteristics of young and elderly subjects during quiet natural standing. Geriatrics E Gerontology International, 10(2), 191198.

Lacour, M., Bernard-Demanze, L., \& Dumitrescu, M. (2008). Posture control, aging, and attention resources: models and posture-analysis methods. Neurophysiologie Clinique/Clinical Neurophysiology, 38(6), 411-421.

Moghadam, M., Ashayeri, H., Salavati, M., Sarafzadeh, J., Taghipoor, K. D., Saeedi, A., et al. (2011). Reliability of center of pressure measures of postural stability in healthy older adults: effects of postural task difficulty and cognitive load. Gait and Posture, 33(4), 651-655.

NICE, (2011) Donepezil, galantamine, rivastigmine and memantine for the treatment of Alzheimer's disease, Available from: http://www.nice.org.uk/ guidance/ta217.

Nebes, R. D., Butters, M. A., Houck, P. R., Zmuda, M. D., Aizenstein, H., Pollock, B. G., et al. (2001). Dual-task performance in depressed geriatric patients. Psychiatry Research, 102(2), 139-151.

Pasma, J. H., Bijlsma, A. Y., van der Bij, M. D., Arendzen, J. H., Meskers, C. G., \& Maier A. B. (2014). Age-related differences in quality of standing balance using a composite score. Gerontology, 60(4), 306-314.

Piirtola, M., \& Era, P. (2006). Force platform measurements as predictors of falls among older people-a review. Gerontology, 52(1), 1-16.

Rubenstein, L. Z. (2006). Falls in older people: epidemiology, risk factors and strategies for prevention. Age and Ageing, 35(suppl 2), ii37-ii41.

Sheikh, J. I., \& Yesavage, J. A. (1986). Geriatric depression scale (GDS): recent evidence and development of a shorter version. Clinical Gerontologist, 5(1-2), $165-173$.

Sheridan, P. L., Solomont, J., Kowall, N., \& Hausdorff, J. M. (2003). Influence of executive function on locomotor function: divided attention increases gait variability in Alzheimer's disease. Journal of the American Geriatrics Society, 51 (11), 1633-1637.

Simões, M. R., Prieto, G., Pinho, M. S., Sobral, M., \& Firmino, H. (2015). Geriatric depression scale. In M. R. Simões, I. Santana, \& Grupo de Estudos de Envelhecimento Cerebral e Demência (Eds.), Escalas e testes na demência (pp. 128-133).Lisboa: Novartis.

Swanenburg, J., de Bruin, E. D., Uebelhart, D., \& Mulder, T. (2009). Compromising postural balance in the elderly. Gerontology, 55(3), 353-360.

Takeshima, N., Islam, M. M., Rogers, M. E., Koizumi, D., Tomiyama, N., Narita, M., et al. (2014). Pattern of age-associated decline of static and dynamic balance in community-dwelling older women. Geriatrics E Gerontology International, 14(3), $556-560$.

Winter, D. A. (1995). Human balance and posture control during standing and walking. Gait \& Posture, 3(4), 193-214.

Woollacott, M., \& Shumway-Cook, A. (2002). Attention and the control of posture and gait: a review of an emerging area of research. Gait and Posture, 16(1), 1-14.

Yogev, G., Hausdorff, J. M., \& Giladi, N. (2008). The role of executive function and attention in gait. Movement Disorders: Official Journal of the Movement Disorder Society, 23(3), 329-472.

Zanotto, T., Bergamin, M., Roman, F., Sieverdes, J. C., Gobbo, S., Zaccaria, M., et al. (2014). Effect of exercise on dual-task and balance on elderly in multiple disease conditions. Current Aging Science, 7(2), 115-136.

Zijlstra, A., Ufkes, T., Skelton, D. A., Lundin-Olsson, L., \& Zijlstra, W. (2008). Do dual tasks have an added value over single tasks for balance assessment in fall prevention programs? A mini-review. Gerontology, 54(1), 40-49. 